\title{
BIOSORPSI LOGAM BESI (Fe) DALAM MEDIA LIMBAH CAIR ARTIFISIAL MENGGUNAKAN BIOSORBEN KULIT PISANG KEPOK (Musa acuminate)
}

\author{
Djamilah Arifiyana*, Vika Ayu Devianti \\ DIII Farmasi, Akademi Farmasi Surabaya \\ "email : djamilah.arifiyana@akfarsurabaya.ac.id
}

Received 03 April 2020

Accepted 22 May 2020

\begin{abstract}
Abstrak
Limbah kulit pisang Kepok telah digunakan untuk menghasilkan biosorben melalui proses yang ramah lingkungan. Limbah kulit pisang Kepok dipotong, dicuci, dikeringkan, dihaluskan dan digunakan sebagai biosorben terhadap logam besi. Penentuan konsentrasi logam besi terhadap proses adsorpsi menggunakan spektroskopi serapan atom. Adsorpsi ion besi terhadap adsorben kulit pisang Kepok menggunakan parameter waktu kontak dan $\mathrm{pH}$. Waktu kontak 30 menit dan pH 6 merupakan kondisi yang sesuai untuk adsorpsi besi. Persentase adsorpsi dan kapasitas adsorpsi yang diperoleh berturut-turut sebesar 86,387\% dan 1,44 mg/g. Hasil penelitian menunjukkan bahwa kulit pisang Kepok, sebagai limbah pertanian dan limbah industri rumahan, sangat berpotensi sebagai adsorben untuk menghilangkan logam beracun seperti besi dalam air.
\end{abstract}

Katakunci: Biosorpsi, Kulit Pisang Kepok, Logam Besi (Fe), Waktu kontak, pH

\begin{abstract}
Kepok banana peels waste were used to produce biosorbent through environment friendly process. It were cut, washed, dried, grounded into powder and used for iron removal. The biosorption of iron on Kepok banana peels has been studied using atomic absorption spectroscopy for metal determination. Iron adsorption onto adsorbent was depended upon the controlling parameters such as contact time and $\mathrm{pH} .30$ minutes and $\mathrm{pH}=6$ were found to be suitable contact time and $\mathrm{pH}$ solution for iron removal. The iron adsorption and adsorption capacity were $86,387 \%$ and $1,44 \mathrm{mg} / \mathrm{g}$, respectively. Study concluded that Kepok banana peels, an agricultural waste and home industry waste, have good potential as an adsorbent to remove toxic metals like iron from water.
\end{abstract}

Keywords: Biosorption, Kepok Banana peels, Iron (Fe), Contact time, pH 


\section{Pendahuluan}

Pertumbuhan industri dan populasi dari hari ke hari menyebabkan permintaan terhadap kebutuhan air semakin meningkat. Disisi lain ekploitasi besarbesaran terhadap sumber daya air menyebabkan penurunan level air permukaan dan air tanah secara terusmenerus. Upaya alternatif terhadap ancaman kekurangan pasokan air terus dilakukan, penggunaan kembali air limbah industri menjadi pilihan yang memungkinkan untuk masa depan (Stoller et al., 2016).

Beberapa metode telah dilakukan untuk mengatasi cemaran logam berat dalam air limbah industri, diantaranya metode pengendapan, koagulasi (Tang et al., 2014), osmosis terbalik (Bakalár et al., 2009), pertukaran ion (Bai \& Bartkiewicz, 2009), fotokatalisis (Chowdhury et al., 2015), ekstraksi pelarut (Cerna, 1995), elektrodialisis, metode elektrokimia, filtrasi dengan membran, dan evaporasi (Jha et al., 2004). Selain metode-metode tersebut, upaya lain dikembangkan untuk mengolah air limbah industri ini, dimana ekstraksi kontaminan menggunakan material padat merupakan metode yang paling menjanjikan. Metode ini didasarkan pada proses adsorpsi yang dapat dilakukan dalam waktu singkat, sederhana, dan tidak memerlukan kondisi operasi yang rumit (Vilardi et al., 2017). Metode ini mewakili metode yang fleksibel untuk ektraksi logam berat dari air limbah dan untuk perolehan kembali logam berat yang masih digunakan di berbagai industri. Dalam dekade terakhir beberapa bentuk material adsorben telah dikembangkan, misalnya bio-adsorben. Disisi lain, limbah pertanian merupakan material yang menjadi potensi besar bagi perkembangan pengolahan air limbah, karena ketersediaan yang melimpah di alam dan biaya yang rendah untuk mendapatkannya (Amarasinghe \& Williams, 2007).

Penelitian mengenai penggunaan kulit pisang sebagai adsorben menarik untuk dilakukan. Pisang sendiri merupakan buah tropis yang banyak ditanam dan telah dibudidayakan di lebih dari 130 negara. Pisang kaya akan polifenol, flavonoid dan dopamin yang ada dalam pulp dan kulitnya; serta $25 \%$ dari buah pisang terdiri dari massa kering dan sisanya adalah air (Albarelli et al., 2011).

Produksi pisang dunia mencapai 81,3 ton per tahun, mengingat bahwa kulitnya sendiri merupakan 25-30\% dari total berat keringnya, itu artinya 5 ton nya merupakan kulit yang dihasilkan sebagai limbah. Di Indonesia sendiri terdapat berbagai macam jenis pisang, salah satunya adalah jenis pisang Kepok. Pisang kepok merupakan jenis pisang dengan ciri fisik ukuran yang besar dan kulit buah yang tebal. Pisang jenis ini banyak dimanfaatkan sebagai bahan baku pembuatan pisang goreng karena teksturnya yang tidak mudah hancur ketika diolah. Karena kelebihan itulah banyak pedagang pisang goreng, baik yang berjualan dipinggir jalan maupun yang berupa industri rumahan menggunakan pisang jenis ini. Kulit pisang merupakan sumber lignin (6\% $12 \%)$, pektin $(10 \%-21 \%)$, selulosa $(7,6 \%$ $-9,6 \%)$ dan hemiselulosa $(6,4 \%-9,4 \%)$. Pektin sendiri merupakan kompleks heteropolisakarida yang mengandung asam galakturonat, arabinosa, galaktosa, dan rhamnosa sebagai konstituen utama gula; gugus karboksil dari asam galakturonat memungkinkan zat pektin mengikat kation logam dalam larutan (Mohapatra et al., 2010). Penelitian mengenai pemanfaatan kulit pisang sebagai adsorben logam berat telah banyak dilakukan (Abdi et al., 2015; Fatmi, 2018; Ashraf et al., 2010; Sirilert \& Maikrang, 2018; Salim et al., 2015), namun penelitian mengenai pemanfaatan kulit pisang kepok terhadap adsorpsi logam besi (Fe) belum banyak dilakukan, sejauh ini adsorben kulit pisang kepok terbatas pada adsorpsi logam $\mathrm{Cu}$ (Alifaturrahma \& Hendriyanto, 2018), Pb (Arninda et al., 2014; Fauici, 2017; Purnama et al., 2015; Wardani \& Wulandari, 2018), Cr (Fauici, 2017), dan Zn (Darmayanti et al., 2012) padahal 
bahaya kontaminan logam Fe terhadap lingkungan juga patut dipertimbangkan. Sehingga dengan demikian pada penelitian ini serbuk biosorben kulit buah pisang kepok disiapkan terlebih dahulu dan kemudian diuji menggunakan larutan logam artifisial yang mengandung logam Fe menggunakan beberapa parameter uji yang meliputi parameter waktu kontak dan $\mathrm{pH}$ larutan uji.

\section{Metode Penelitian \\ Alat dan bahan}

Alat yang digunakan dalam penelitian ini meliputi oven (Memmert), neraca analitik (OHaus CP214), stirrer (Thermo Scientific Cimarec SP88850105) serta Spektrofotometer Serapan Atom (Perkin Elmer Analys 100), dan alat-alat gelas yang terdiri dari kaca arloji, labu ukur, gelas ukur, batang pengaduk, pipet tetes, pipet volume, erlenmeyer, dan kertas saring.

Bahan yang digunakan meliputi Logam $\mathrm{FeSO}_{4} \cdot 7 \mathrm{H}_{2} \mathrm{O}$ (Merck), $\mathrm{HCl}$ (Merck), $\mathrm{NaOH}$ (Merck) dan aqua deionisasi (WaterOne). Semua bahan yang telah disebutkan diatas memiliki kualitas pro analitik, serta kulit pisang kepok.

\section{Preparasi biosorben}

Kulit pisang Kepok (Musa acuminate) pada penelitian ini diperoleh dari pedagang pisang goreng dipinggir jalan. Kulit pisang Kepok yang diperoleh kemudian dibersihkan dengan air mengalir, dan dibilas kembali dengan aqua deionisasi. Kulit pisang Kepok yang telah bersih dipotong kecil, dikeringkan di bawah sinar matahari selama 5 hari, kemudian dikeringkan dalam oven pada suhu $70^{\circ} \mathrm{C}$ selama 3 jam. Kulit pisang Kepok yang telah kering dihaluskan dengan blender dan diayak dengan ayakan ukuran 100 mesh. Metode preparasi adsorben ini diadaptasi dari penelitian yang dilakukan oleh Sirilert \& Maikrang (2018). Biosorben kulit pisang Kepok selanjutnya disimpan dalam wadah yang berisi silika gel untuk menghilangkan kelembaban.

\section{Preparasi larutan logam $\mathrm{Fe}$}

Larutan stok $\mathrm{Fe}$ dengan konsentrasi 1000 ppm disiapkan dengan melarutkan sejumlah logam $\mathrm{FeSO}_{4} \cdot 7 \mathrm{H}_{2} \mathrm{O}$ dalam aqua deionisasi. Selanjutnya dibuat larutan kerja Fe dengan konsentrasi sesuai kebutuhan melalui pengenceran larutan stok $\mathrm{Fe}$ dengan aqua deionisasi.

\section{Metode analisis pengaruh waktu kontak}

Pada parameter ini dilakukan pengujian waktu kontak adsorpsi optimum, dimana waktu adsorpsi divariasikan pada 10, 20, 30, 40 dan 50 menit. Adsorben kulit pisang ditimbang sebanyak 1,5 gram, kemudian kedalam erlenmeyer yang telah berisi adsorben ditambahkan larutan Fe 50 ppm sebanyak $50 \mathrm{ml}$, diatur $\mathrm{pH}$ campuran pada $\mathrm{pH} 6$. Campuran kemudian diaduk dengan kecepatan $250 \mathrm{rpm}$ selama variasi waktu yang telah ditentukan. Hasil pengadukan selanjutnya disaring, filtrat hasil penyaringan dianalisis konsentrasi logam $\mathrm{Fe}$ yang tersisa dengan AAS. Hasil persentase rata-rata adsorpsi tertinggi merupakan data waktu optimum.

\section{Metode analisis pengaruh $\mathrm{pH}$}

Analisis untuk mengetahui $\mathrm{pH}$ optimum dilakukan dengan prosedur yang sama dengan prosedur optimasi waktu kontak. Adsorben ditimbang sebanyak 1,5 gram, kemudian ditambah dengan larutan logam Fe 50 ppm sebanyak $50 \mathrm{ml}$. pH campuran selanjutnya diatur pada variasi $\mathrm{pH} \mathrm{3,} \mathrm{4,} \mathrm{5,} 6$ dan 7, dan diadsorpsi selama waktu kontak optimum dengan kecepatan pengadukan $250 \mathrm{rpm}$. Pengaturan $\mathrm{pH}$ dilakukan dengan penambahan $\mathrm{HCl}$ atau $\mathrm{NaOH}$. Hasil adsorpsi disaring, filtrat yang diperoleh kemudian dianalisis konsentrasi logam $\mathrm{Fe}$ tersisa. Hasil persentase rata-rata adsorpsi tertinggi merupakan data $\mathrm{pH}$ optimum.

\section{Analisis \%Adsorpsi}

Data logam Fe yang diperoleh dari masing-masing parameter dihitung untuk mendapatkan persentase adsorpsi dan 
kapasitas adsorpsi melalui persamaan (1) dan (2).

$$
\begin{array}{r}
\text { \%Adsorpsi }=\frac{\mathrm{C}_{0}-\mathrm{C}}{\mathrm{C}_{0}} \times 100 \% \ldots \\
q=\frac{\left(C_{0}-C\right)}{m} \times V \ldots
\end{array}
$$

Di mana, $\mathrm{C}_{0} \quad(\mathrm{ppm})$ merupakan konsentrasi awal logam; C (ppm) merupakan konsentrasi logam setelah melalui proses adsorpsi; q $(\mathrm{mg} / \mathrm{g})$ merupakan jumlah ion logam yang teradsorpsi tiap satuan massa adsorben, $\mathrm{V}$ (L) merupakan volume larutan logam yang digunakan pada proses adsorpsi; $m$ (gram) merupakan massa adsorben kulit pisang yang digunakan.

\section{Hasil dan Pembahasan}

Penelitian ini diawali dengan preparasi biosorben kulit pisang kepok. Pada penelitian ini kulit pisang kepok diperoleh dari pedagang pisang goreng yang ada daerah Surabaya. Kulit pisang Kepok selanjutnya disortasi basah untuk menghilangkan debu dan kotoran lainnya. Kulit pisang dipotong kecil untuk mempercepat penguapan kandungan air oleh sinar matahari, selanjutnya dikeringkan dalam oven untuk memastikan seluruh kandungan air telah hilang. Kulit pisang selanjutnya dihaluskan untuk memperbesar luas permukaan biosorben. Biosorben selanjutnya diayak dengan ayakan berukuran 100 mesh, hal ini bertujuan untuk menyeragamkan ukuran partikel biosorben.

\section{Pengaruh waktu kontak}

Waktu kontak merupakan faktor yang penting dalam proses adsorpsi, hal ini karena berkaitan dengan efisiensi adsorpsi dan kecepatan reaksi adsorpsi. Pengaruh variasi waktu kontak terhadap \%Adsorpsi ditunjukkan pada Gambar 1.

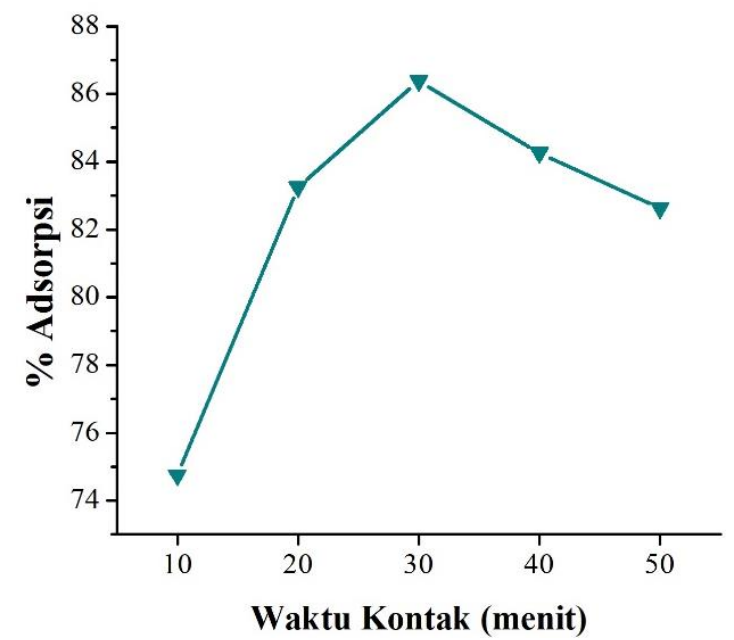

Gambar 1. Grafik hasil adsorpsi logam Fe terhadap variasi waktu kontak

Berdasarkan hasil yang telah diperoleh, sejak 10 menit pertama biosorben kulit pisang kepok telah menunjukkan kemampuannya sebagai adsorben, hal ini dibuktikan dengan perolehan \%Adsorpsi yang cukup tinggi, yakni sebesar $74,747 \%$. Hasil ini merupakan \%Adsorpsi terendah diantara kelima variasi waktu kontak yang dilakukan. Hal ini disebabkan karena pada waktu kontak 10 menit tersebut, gugus fungsi pada adsorben belum maksimal untuk berinteraksi dengan logam $\mathrm{Fe}$, sehingga belum banyak gugus fungsi yang mengadsorp logam $\mathrm{Fe}$ (Safrianti et al., 2012). Selanjutnya pada waktu kontak 20 hingga 30 menit mengalami peningkatan \%Adsorpsi, dan dicapai \%Adsorpsi tertinggi pada waktu kontak 30 menit, yaitu sebesar $86,387 \%$. Menurut penelitian yang dilakukan oleh Arunakumara et al. (2013), proses adsorpsi sangat dipengaruhi oleh gugus fungsi karboksil pada polimer asam galakturonat, penyusun utama senyawa pektin, dimana pektin merupakan senyawa dengan persentase tertinggi dalam kulit pisang. Dalam sistem larutan, gugus fungsi karboksil pada polimer asam galakturonat ini terionisasi menjadi ion negatif $\left(-\mathrm{COO}^{-}\right)$, hal inilah yang menyebabkan kulit pisang dapat mengadorpsi logam berat yang bermuatan positif. Gugus fungsi lainnya yang berkontribusi terhadap proses adsorpsi logam berat adalah adalah gugus fungsi 
amin (-NH), karboksil (-OH) dan karbonil $(=\mathrm{O})$ (Ahmad \& Danish, 2018), serta tambahan gugus sulfidril dan fosforil yang merupakan penyusun dinding sel (Chojnacka \& Mikulewicz, 2019). Biosorpsi sendiri merupakan kombinasi dari berbagai macam proses reaksi seperti reaksi pertukaran ion, pembentukan kompleks dan reaksi reduksi-oksidasi, namun didominasi oleh reaksi pertukaran ion (Chojnacka \& Mikulewicz, 2019).

Namun setelah waktu kontak optimum tercapai, terjadi penurunan \%Adsorpsi berturut-turut pada 40 dan 50 menit. Waktu kontak optimum yang diperoleh pada penelitian ini serupa dengan waktu kontak optimum penelitian yang dilakukan oleh Pranoto et al., (2020), yaitu 30 menit. Pranoto et al. memperoleh \%Adsorpsi sebesar 90,06\% dan kapasitas adsorpsi $0,54 \mathrm{mg} / \mathrm{g}$, meski nilai \%Adsorpsi penelitian Pranoto et al. lebih tinggi dari hasil penelitian ini, namun kapasitas adsorpsi pada penelitian ini lebih tinggi, yaitu sebesar 1,44 mg/g. \%Adsorpsi dan Kapasitas adsorpsi pada penelitian ini memiliki kecenderungan yang sama (Gambar 1 dan Tabel 1).

Tabel 1. Hasil Kapasitas Adsorpsi terhadap parameter Waktu Kontak dan $\mathrm{pH}$

\begin{tabular}{cccccc}
\hline $\begin{array}{c}\text { Waktu } \\
\text { Kontak } \\
\text { (menit) }\end{array}$ & $\mathbf{1 0}$ & $\mathbf{2 0}$ & $\mathbf{3 0}$ & $\mathbf{4 0}$ & $\mathbf{5 0}$ \\
\hline $\begin{array}{c}\mathrm{q} \\
(\mathrm{mg} / \mathrm{g})\end{array}$ & 1,25 & 1,39 & 1,44 & 1,40 & 1,38 \\
\hline $\mathbf{p H}$ & $\mathbf{3}$ & $\mathbf{4}$ & $\mathbf{5}$ & $\mathbf{6}$ & $\mathbf{7}$ \\
\hline $\begin{array}{c}\mathrm{q} \\
(\mathrm{mg} / \mathrm{g})\end{array}$ & 0,72 & 0,68 & 0,71 & 1,44 & 1,05 \\
\hline
\end{tabular}

Pada waktu kontak 40 dan 50 menit, secara berturut-turut \%Adsorpsi mengalami penurunan, menurut Yetri \& Hidayati (2018) hal ini dapat dikarenakan adsorbat logam besi mengalami desorpsi, yaitu lepasnya ion adsorbat yang sudah terikat dengan adsorben kedalam sistem larutan akibat lemahnya ikatan.

\section{Pengaruh $p H$ larutan}

Salah satu faktor penting dalam proses adsorpsi logam berat adalah $\mathrm{pH}$ larutan. Pengaruh $\mathrm{pH}$ larutan pada penelitian ini dilakukan pada rentang 3-7. Sebagaimana ditunjukkan pada Gambar 2, adsorpsi maksimum dari logam $\mathrm{Fe}$ terjadi pada $\mathrm{pH}$ 6. Pada variasi $\mathrm{pH} \mathrm{3,} \mathrm{4,} \mathrm{dan} 5$ diperoleh \%Adsorpsi yang relatif rendah, yakni berkisar antara 40-45\%. Rendahnya perolehan \%Adsorpsi ini disebabkan oleh banyaknya ion $\mathrm{H}^{+}$yang ada disekitar permukaan adsorben, sehingga menyebabkan permukaan adsorben menjadi bermuatan positif dan menimbulkan gaya tolak terhadap ion logam, dengan kata lain ion logam bersaing dengan ion $\mathrm{H}^{+}$yang ada dalam sistem untuk mencapai sisi aktif biosorben yang masih tersedia untuk berikatan. Pada $\mathrm{pH}$ rendah permukaan adsorben bermuatan positif karena terjadinya protonasi. Seiring dengan meningkatnya nilai $\mathrm{pH}$, konsentrasi $\mathrm{H}^{+}$dalam sistem berkurang sehingga menyebabkan meningkatnya \%Adsorpsi. Selanjutnya, adsorpsi mengalami penurunan pada $\mathrm{pH}$ yang lebih tinggi $(\mathrm{pH}>6)$ karena terjadinya pembentukan kompleks hidroksilasi terlarut dari ion logam dan kompetisinya dengan sisi aktif adsorben (Reddy et al., 2011; Ngabura et al., 2018).

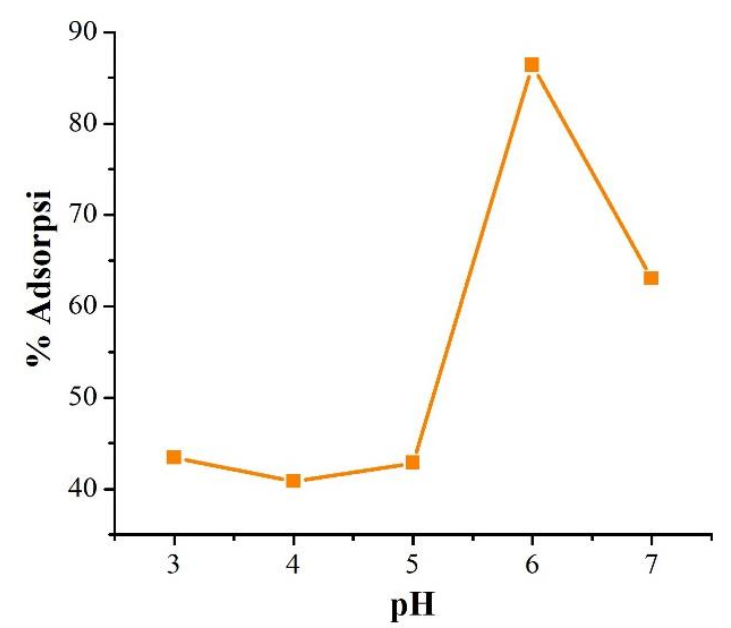

Gambar 2. Grafik hasil adsorpsi logam Fe terhadap variasi $\mathrm{pH}$ larutan 
Pada pH 6 diperoleh \%Adsorben tertinggi, namun mengalami penurunan pada $\mathrm{pH}$ 7. Penurunan ini disebabkan oleh pada $\mathrm{pH}$ yang lebih tinggi sisi adsorpsi menjadi tidak aktif. Tidak aktifnya sisi adsorpsi ini disebabkan oleh reaksi antara kation logam dengan ion $\mathrm{HO}^{-}$sehingga terbentuk hidroksida logam. Hal ini juga diperkuat oleh penelitian yang dilakukan oleh Pranoto et al. (2020), yang juga menggunakan $\mathrm{Fe}$ sebagai adsorbat, dimana pada $\mathrm{pH}$ yang relatif tinggi baik \%Adsorpsi maupun kapasitas adsorpsi mengalami penurunan yang menunjukkan bahwa larutan $\mathrm{Fe}$ mulai mengalami pengendapan membentuk $\mathrm{Fe}(\mathrm{OH})_{2}$ yang ditandai dengan adanya warna kuning pada larutan, sehingga proses adsorpsi sulit terjadi. Terbentuknya senyawa logam hiroksida pada pengaturan $\mathrm{pH}$ yang relatif tinggi sebagai akibat dari adanya ion $\mathrm{OH}$ yang bermuatan negatif dengan ion logam yang bermuatan positif juga dikemukaan oleh Anwar et al., (2010). Kecenderungan pengaruh variasi $\mathrm{pH}$ terhadap hasil \%Adsorpsi pada penelitian ini mirip dengan kecenderungan pada penelitian yang dilakukan oleh Reddy et al., (2010) dan Reddy et al., (2011), di mana \%Adsorpsi mengalami kenaikan hingga optimum pada $\mathrm{pH}$ 6, selanjutnya mengalami penurunan pada $\mathrm{pH}$ 7. Hal ini disebabkan pada pengaturan nilai $\mathrm{pH}$ sistem yang lebih tinggi $(\mathrm{pH}>6)$, menyebabkan biosorpsi logam mengalami penurunan akibat reaksi hidrolisis ion logam, hal ini telah teramati pada biosorben-biosorben lain yang mengandung asam karboksilat (Reddy et al., 2010).

Pada penelitian ini, perolehan \%Adsorpsi dan kapasitas adsorpsi memiliki kencenderungan yang sama, baik pada parameter waktu kontak maupun parameter $\mathrm{pH}$ larutan (Tabel 1). Dengan demikian, serbuk kulit buah pisang dapat digunakan untuk adsorpsi logam berat yang larut dalam air limbah. Pada dasarnya toksisitas logam berat tergantung pada konsentrasi, kelarutan dan organisme target yang akan dipengaruhi. Meski mayoritas logam berat dapat berperan sebagai nutrisi penting bagi tubuh hingga kadar tertentu, namun pengaruh bahaya terhadap kesehatan dapat direduksi jika logam berat ini dihilangkan dari lingkungan (Vörösmarty et al., 2000)

\section{Kesimpulan}

Kulit pisang kepok dapat digunakan sebagai biosorben terhadap logam $\mathrm{Fe}$. Pada penelitian ini, waktu kontak optimum dicapai pada waktu kontak 30 menit dan $\mathrm{pH}$ larutan 6, dimana persen adsorpsi yang diperoleh sebesar $86,387 \%$ dengan kapasitas adsorpsi sebesar $1,44 \mathrm{mg} / \mathrm{g}$. Penelitian ini juga dapat digunakan untuk menyimpulkan bahwa dibandingkan penggunaan bahan kimia, bahan limbah pertanian atau limbah industri rumahan seperti kulit pisang juga dapat digunakan untuk mengurangi cemaran logam berat air limbah industri untuk mengatasi polusi air.

\section{Ucapan Terima Kasih}

Penulis mengucapkan terimakasih kepada DRPM Kemenristekdikti yang telah mendanai penelitian ini melalui skema Hibah Penelitian Dosen Pemula Tahun 2020 (Nomor: 145/SP2H/LTMONO/LL7/2020). 


\section{Daftar Pustaka}

Abdi C., Khair R.M., Saputra M.W. 2015. Pemanfaatan Limbah Kulit Pisang Kepok (Musa acuminate L.) sebagai Karbon Aktif untuk Pengolahan Air Sumur Kota Banjarbaru: Fe dan Mn, Jukung Jurnal Teknik Lingkungan, 1 (1), 8-15.

Ahmad T., \& Danish M. 2018. Prospects of banana waste utilization in wastewater treatment: A review. Journal of Environmental Management, 206, 330-348.

Albarelli J., Rabelo R., Santos D., Beppu M. 2011. Effects of supercritical carbon dioxide on waste banana peels for heavy metal removal. $J$. Supercrit. Fluids, 58(3); 343-351.

Alifaturrahma P. \& Hendriyanto O. 2018. Pemanfaatan Kulit Pisang Kepok Sebagai Adsorben untuk Menyisihkan Logam Cu, Jurnal Envirotek, 8 (2), ISSN: 2085-501X.

Amarasinghe B.M.W.P.K., \& Williams R.A. 2007. Tea waste as a low cost adsorbent for the removal of $\mathrm{Cu}$ and $\mathrm{Pb}$ from wastewater. Chem. Eng. J., 132, 299-309.

Anwar J., Shafique U., Waheed-uzZaman, Salman M., Dar A., Anwar S. 2010. Removal of $\mathrm{Pb}(\mathrm{II})$ and $\mathrm{Cd}$ (II) from water by adsorption on peels of banana. Bioresource Technology, 101, 1752-1755.

Arninda A., Sjahrul M., Zakir M. 2014. Adsorpsi Ion Logam $\mathrm{Pb}(\mathrm{II})$ dengan Menggunakan Kulit Pisang Kepok (Musa Paradisiaca Linn). Indonesia Chimica Acta, 9 (2), 21-26.

Arunakumara K.K.I.U., Walpola B.C., and Yoon Min-Ho. 2013. Banana Peel: A Green Solution for Metal Removal from Contaminated Waters. Korean Journal of Enviromental Agriculture, 32(2), 108-116.

Ashraf M.A., Maah M.J., and Yusoff I. 2010. Study of Banana Peel (Musa sapientum) as a Cationic Biosorbent. American-Eurasian J. Agric. \& Environ. Sci., 8 (1), 07-17.
Bai Y., and Bartkiewicz B. 2009. Removal of Cadmium from Wastewater Using Ion Exchange Resin Amberjet 1200H Columns. Polish J. of Environ. Stud., 18(6), 1191-1195.

Bakalár T., Búgel M., and Gajdošová L. 2009. Heavy metal removal using reverse osmosis. Acta Montanistica Slovaca Ročník, 14 (3), 250-253.

Cerna M. 1995. Use of Solvent Extraction for the Removal of Heavy Metals from Liquid Wastes. Enviromental Monitoring and Assesment, 34 (20), 151-162. doi:10.1007/bf00546029.

Chojnacka K. \& Mikulewicz M. 2019. Green analytical methods of metals determination in biosorption studies, Trends in Analytical Chemistry, 116, 254-265.

Chowdhury P., Elkamel A., \& Ray, A.K. 2015. Chapter 2 Photocatalytic Processes for the Removal of Toxic Metal Ions. Heavy Metals in Water: Presence, Removal dan Safety, The Royal Society of Chemistry, 25-43.

Darmayanti, Rahman N., Supriadi. 2012. Adsorpsi Timbal $(\mathrm{Pb})$ dan Zink (Zn) dari Larutannya Menggunakan Arang Hayati (Biocharcoal) Kulit Pisang Kepok Berdasarkan Variasi pH. J. Akad. Kim., 1 (4), 159-165.

Fatmi D. \& Putra B.H. 2018. Studi Efektifitas Limbah Kulit Pisang (Musa acuminate) Sebagai Biosorben Logam Berat Seng ( $\mathrm{Zn}$ ). MENARA Ilmu, XII (9), 40-50.

Fauici M. 2017. Adsorpsi Ion $\mathrm{Pb}$ (II) dan $\mathrm{Cr}$ (VI) Menggunakan Arang Kulit Pisang Kepok (Musa Paradisiaca Linn) pada Limbah Cair Industri (Studi Kasus PT. Sermani Steel). Tesis, Universitas Hasanuddin, Makassar.

Jha M.K, Kumar V., Maharaj L., and Singh R. 2004. Studies on Leaching and Recycling of Zinc from Rayon Waste Sludge. J. Ind. Eng. Chem., Res., 43, 1284-1285.

Mohapatra D., Mishra S., Sutar N. 2010. Banana and its by-product 
utilisation: An overview, AN Overv., J.Sci. Ind. Res., 69, 323-329. Ngabura M., Hussain S.A., Ghani W.A., Jami M.S., Tan Y.P. 2018. Utilization of Renewable Durian Peels for Biosorption of Zinc from Wastewater. Journal of Environmental Chemical Engineering, 6(2), 2528-2539.

Pranoto P., Martini T., Maharditya W. 2020. Uji Efektivitas dan Karakterisasi Komposit Tanah Andisol/Arang Tempurung Kelapa Untuk Adsorpsi Logam Berat Besi (Fe). ALCHEMY Jurnal Penelitian Kimia, 16(1), 50-66.

Purnama P.E., Dewi I.G.A.K.S.P., dan Ratnayani K. 2015. Kapasitas Adsorpsi Beberapa Jenis Kulit Pisang Teraktivasi $\mathrm{NaOH}$ Sebagai Adsorben Logam Timbal (Pb). Jurnal Kimia, 9 (2), 196-202.

Reddy D.H.K., Seshaiaha K., Reddy A.V.R., Raoc M.M., Wang M.C. 2010. Biosorption of $\mathrm{Pb}^{2+}$ from aqueous solutions by Moringa oleifera bark: Equilibrium and kinetic studies. Journal of Hazardous Materials, 174, 831-838.

Reddy D.H.K., Ramana D.K.V., Seshaiah K., Reddy A.V.R. 2011. Biosorption of $\mathrm{Ni}(\mathrm{II})$ from aqueous phase by Moringa oleifera bark, a low cost biosorbent. Desalination, 268, 150 157.

Safrianti I., Wahyuni N., and Zaharah T. 2012. Adsorpsi Timbal (II) Oleh Selulosa Limbah Jerami Padi Teraktivasi Asam Nitrat, Pengaruh pH dan Waktu Kontak, Jurnal Kimia Khatulistiwa. 1(1), 1-7.

Salim R.M., Chowdhury A.J.K., Rayathulhan R., Yunus K., Sarkar Md.Z.I. 2015. Biosorption of $\mathrm{Pb}$ and $\mathrm{Cu}$ from aqueous solution using banana peel powder. Desalination and Water Treatment, 57 (1), 303-
314.

Sirilert M. \& Maikrang K. 2018. Adsorpstion Isotherm of Some Heavy Metal in Water on Unripe dan Ripe Peel of Banana. Naresuan University Journal: Science and Technology, 26 (1), 128-141.

Stoller M., Azizova G., Mammadova A., Vilardi G., Di Palma L., Chianese A. 2016. Treatment of olive oil processing wastewater by ultrafiltration, nanofiltration, reverse osmosis and biofiltration. Chem. Eng. Trans., 47, 409-414.

Tang X., Zheng H., Teng H., Sun Y., Guo J., Xie W., Yang Q. \& Chen W. 2014. Chemical coagulation process for the removal of heavy metals from water: a review. Desalination and Water Treatment, 57 (4), 1733-1748.

Vilardi G., Di Palma L., Verdone N. 2017. Heavy metals adsorption by banana peels micro-powder. Equilibrium modeling by non-linear models. Chinese Journal of Chemical Engineering, 26 (3), 455-464.

Vörösmarty C.J., Green P., Salisbury J., Lammers R.B. 2000. Global water resources: Vulnerability from climate change and population growth. Science, 289, 284-288.

Wardani G.A. \& Wulandari W.T. 2018. Pemanfaatan Limbah Kulit Pisang Kepok (Musa acuminate) sebagai Biosorben Ion Timbal (II). Jurnal Kimia VALENSI: Jurnal Penelitian dan Pengembangan Ilmu Kimia, 4 (2), 143-148.

Yetri Y. \& Hidayati R. 2018. Kemampuan Kulit Buah

Kakao (Theobromacacao) Sebagai Biosorben Ion Logam $\mathrm{Hg}(\mathrm{II})$ dan $\mathrm{Ni}(\mathrm{II})$, Seminar Nasional Industri dan Teknologi (SNIT), Politeknik Negeri Bengkalis. 